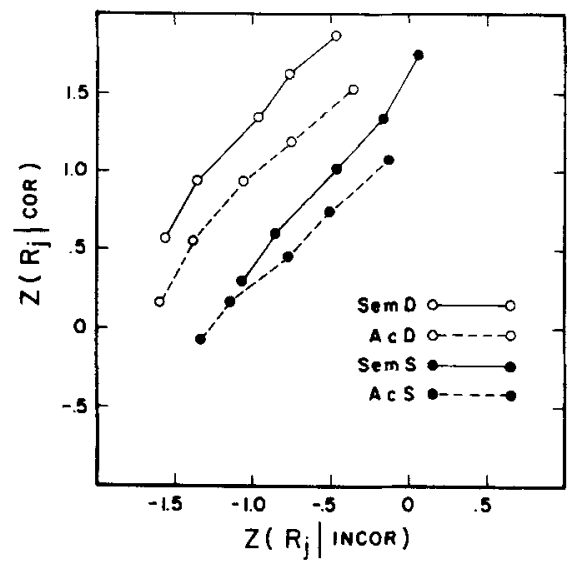

Fig. 1. The receiver operator characteristic (Type II) averaged over all groups for the four OL-IL similarity conditions. Each point is based upon a number of responses that ranges between 156 and 1,656 .

strong confidence in either correctness or incorrectness of responses. For example, the probability that an $S$ uses a 5 rating (very confident response is correct) when actually incorrect, $\mathrm{P}$ ( 5 | INCOR), is slightly greater in the similar conditions. P(5 | INCOR) was: SemD, 0.059; SemS, 0.148 ; AcD, 0.055; AcS, 0.091. Nevertheless, there is some evidence that Ss' criterion placement for the low-confidence categories changed from the similar conditions to the dissimilar conditions. For example, $\mathrm{P}(0 \mid \mathrm{INCOR})$ is lower in the similar conditions, e.g., SemD, 0.680, SemS, 0.475, AcD, 0.676, AcS, 0.543 , data that are not compatible with the fixed-criteria notion since noise should overlap more with the signal distribution in the similar conditions and thus produce more errors in that condition. This suggests that an $S$ adopts a generally more conservative strategy in evaluating responses (at least for the $R_{j}=0$ decision) perhaps because $S$ realizes the difficulty of the similar material, i.e., he is sensitive to the reduced $\mathrm{d}^{\prime}$.

The present results suggest that Es, who would employ traditional measures in experiments where Ss are not forced to respond, are risking the confounding influences of the criterion problem to. which Murdock (1966) refers. It seems quite probable that many experimental manipulations do not passively affect $\mathrm{Ss}^{\prime}$ behavior but initiate the active shifting of response criteria by $\mathrm{Ss}$ who are adopting strategies toward the experimental tasks before them.

\section{REFERENCES}

BADDELEY, A. D., \& DALE, H. C. A. The effect of semantic similarity on retroactive interference in long- and short-term memory. Journal of Verbal Learning \& Verbal Behavior, $1966,5,417-420$.

BATTIG, W. F., \& MONTAGUE, W. E. Category norms for verbal items in 56 categories: A replication and extension of the Connecticut Category Norms. Joumal of Experimental Psychology, 1969, 80 (3, Part 2).

DALE, H. C. A. Retroactive interference in short-term memory. Nature, 1964, 203, 1408.

KATZ, L. A comparison of Type II operating characteristics derived from confidence ratings and from latencies. Perception \& Psychophysics, 1970, 8, 65-68.
MURDOCK, B. B., JR. The criterion problem in short-term memory. Joumal of Experimental Psychology, 1966, 72, 317-324.

POLLACK, I., \& DECKER, L. R. Confidence ratings, message reception, and the receiver operating characteristic. Journal of the Acoustical Society of America, 1958, 30, 286-292.

ROBINSON, E. S. The "similarity" factor in retroaction. American Journal of Psychology, 1927, 39, 297-312.

WICKELGREN, W. A. Acoustic similarity and retroactive interference in STM. Journal of Verbal Leaming \& Verbal Behavior, 1965, 4, 53-61.

\title{
The effects of state instructions and schedules of reinforcement on resistance to extinction*
}

\author{
RONALD K. PARKER $†$ \\ Florida State University, Tallahassee, Fla. 32306
}

College females $(\mathrm{N}=70)$ were used in an experimental design manipulating state instructions and seven schedules of reinforcement ( $0 \%$ to $100 \%$ in increments of $1 / 6$ ). The state instructions required the Ss to guess before each trial if they were ever going to be reinforced again throughout 30 acquisition trials and 60 extinction trials-i.e., the $S$ guessed whether she was in an experimental state of acquisition or extinction. The most lean schedules of reinforcement (1/6 and 2/6) were most resistant to extinction; however, the resistance to extinction was not related in an orderly fashion to schedule of reinforcement.

Parker (1967) distinguished between the typical "trial instructions" (TI) employed in probability learning experiments in which the $S$ guessed before each trial if he was to be rewarded on the next trial (e.g., Grant, Hake, \& Hornseth, 1951) and "state instructions" (SI) in which the S guessed if he would ever be rewarded again throughout the remainder of the

*This research was supported by a Florida State University Research Council award. PARK 35-036.

Now at the Center for Advanced Study in Fducation, The City University of New York. experimental session-i.e., the $S$ guessed whether or not he was in an experimental state of acquisition or extinction. Using children as Ss, he manipulated instructions, schedules of reward, and magnitude of reward in a 2 by 2 by 2 factorial design. The "state" and "trial" instructions produced distinctly different behavior in acquisition and extinction, and, using $50 \%$ and $100 \%$ schedules of reward, the partial reinforcement effect (PRE) was more clearly evidenced in SI than in the TI.

This experiment represents one in a series of studies designed to explore the 


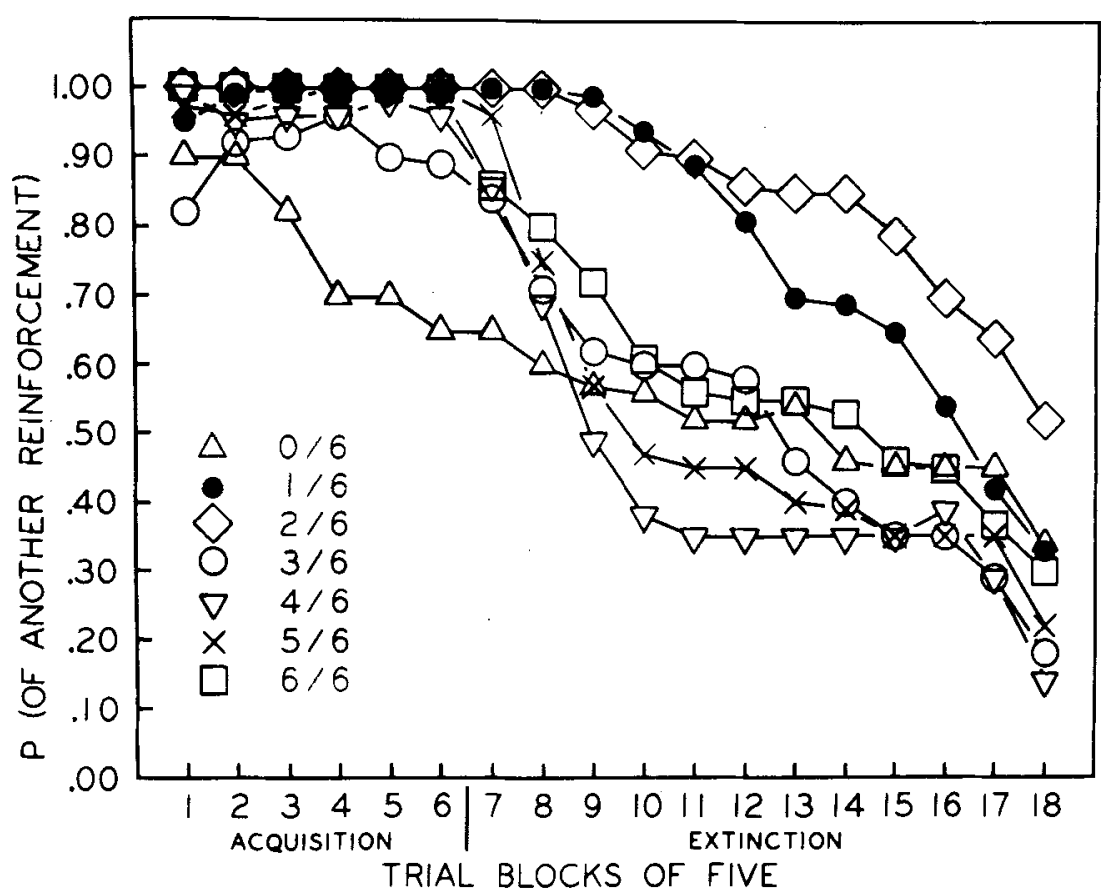

independent variables that influence SI. The study used college femates as $\mathrm{Ss}$ to obtain Ss more rational than children and to bring some feminine beauty into the author's lab.

Seven schedules of reinforcement (knowledge of results) were manipulated from $0 \%$ to $100 \%$ increments of $1 / 6$. The dependent variable was the S's discriminations ("yes" or "no" response) of whether she was in an experimental state of acquisition or extinction throughout 30 acquisition trials and 60 extinction trials. It was predicted that the PRE would be obtained in this direct test of the discrimination hypothesis explanation of the PRE (see Lewis, 1960). SUBJECTS

The Ss were 70 college females at Florida State University who participated in this study as a course requirement in introductory psychology. They were assigned randomly to seven experimental groups.

\section{APPARATUS}

A deck of $903 \times 5$ in. cards served as the experimental stimuli. Depending on the treatment group, part of the first 30 (acquisition) cards were marked with a large black " $X$ " on one side, while the extinction cards (31 through 90) were blank. For example, an $\mathrm{S}$ on a $50 \%$ schedule of reinforcement would have 15 blank cards and 15 " $X$ " cards randomly distributed in the 30 acquisition "trials" or cards. The $\mathrm{S}$ recorded her SI responses by checking the appropriate blank on a mimeographed answer sheet.

\section{PROCEDURE}

The Ss were seen individually in a
Fig. 1. Acquisition and extinction scores as a function of schedule of reinforcement.

not reach statistical significance. This finding is important regarding the equality of the treatment groups at the terminal level of acquisition. In the absence of any reinforcement, the $0 \%$ group's response level began to fall after only 10 trials.

Extinction

The extinction data of 12 trial blocks of five responses each were subjected to an analysis of variance ( $0 \%$ group is omitted). The main effect of schedule of reinforcement was significant $[F(5,54)=2.72, p<.03]$. In examining Fig. 1, a picture emerges of the differential effects of schedules of reinforcement.

\section{DISCUSSION}

The importance of this investigation is the extension of the use of SI to seven schedules of reinforcement. The discrimination hypothesis interpretation of the PRE provides an explanation of these results in that the most lean schedules of reinforcement $(1 / 6$ and $2 / 6)$ were more resistant to extinction than the continuous schedule; however, the S's expectancy of obtaining any more reinforcements throughout the experiment was not related in an orderly fashion to the schedules of reinforcement.

Several procedural improvements have recently been initiated in this research program. First, a carousel slide projector is used to present the stimuli. Second, in some studies we are requiring the same $S$ to make both state and trial decisions. Both of these instructions can be understood by children as young as sixth graders. Third, Ss are asked to make decisions about whether or not they will be reinforced over a short run of trials rather than following SI or TI. Fourth, rather than asking the S to make a binary response (yes-no) in SI or TI, a more sensitive dependent variable is for the $S$ to assign an exact probability to his decision. Fifth, rather than use naive $S_{s}$ in only one treatment condition, it appears worthwhile to use a Latin square design in which each $S$ is presented all treatment conditions in all possible orders.

\section{REFERENCES}

GRANT, D. A., HAKE, H. W., \& HORNSETH, J. P. Acquisition and extinction of a verbal conditioned response with differing percentages of reinforcement. Journal of Experimental Psychology, 1951, 42, 1-5.

LEWIS, D. J. Partial reinforcement: A selective review of the literature since 1950 . Psychological Bulletin, 1960, 57, 1-28.

PARKER, R. K. The effects of instructions, schedules of reward and magnitude of reward on the discrimination of acquisition and extinction phases of learning. Journal of F'. Jerimental Psychology, 1967, 75. 210-216. NOTE

1. Verbatim instructions are available on request. 